\title{
2004s-09 \\ Dynamic Duopoly with Congestion Effects
}

\author{
Didier Laussel, Maxime de Montmarin, \\ Ngo Van Long
}

Série Scientifique
Scientific Series

Montréal

Février 2004

(C) 2004 Didier Laussel, Maxime de Montmarin, Ngo Van Long. Tous droits réservés. All rights reserved. Reproduction partielle permise avec citation du document source, incluant la notice (C).

Short sections may be quoted without explicit permission, if full credit, including (C) notice, is given to the source.
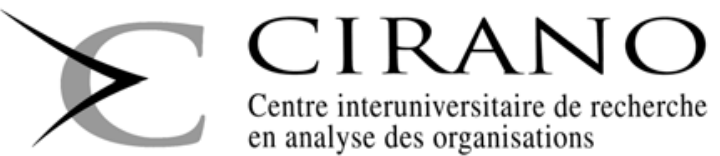

Centre interuniversitaire de recherche en analyse des organisations 


\section{CIRANO}

Le CIRANO est un organisme sans but lucratif constitué en vertu de la Loi des compagnies du Québec. Le financement de son infrastructure et de ses activités de recherche provient des cotisations de ses organisations-membres, d'une subvention d'infrastructure du ministère de la Recherche, de la Science et de la Technologie, de même que des subventions et mandats obtenus par ses équipes de recherche.

CIRANO is a private non-profit organization incorporated under the Québec Companies Act. Its infrastructure and research activities are funded through fees paid by member organizations, an infrastructure grant from the Ministère de la Recherche, de la Science et de la Technologie, and grants and research mandates obtained by its research teams.

\section{Les organisations-partenaires / The Partner Organizations}

PARTENAIRE MAJEUR

. Ministère du développement économique et régional [MDER]

PARTENAIRES

. Alcan inc.

. Axa Canada

. Banque du Canada

. Banque Laurentienne du Canada

. Banque Nationale du Canada

. Banque Royale du Canada

. Bell Canada

. BMO Groupe Financier

. Bombardier

. Bourse de Montréal

. Caisse de dépôt et placement du Québec

. Développement des ressources humaines Canada [DRHC]

. Fédération des caisses Desjardins du Québec

. GazMétro

. Hydro-Québec

. Industrie Canada

. Ministère des Finances [MF]

. Pratt \& Whitney Canada Inc.

. Raymond Chabot Grant Thornton

. Ville de Montréal

. École Polytechnique de Montréal

. HEC Montréal

. Université Concordia

. Université de Montréal

. Université du Québec à Montréal

. Université Laval

. Université McGill

Associe A :

. Institut de Finance Mathématique de Montréal (IFM²)

. Laboratoires universitaires Bell Canada

. Réseau de calcul et de modélisation mathématique $\left[\mathrm{RCM}^{2}\right]$

. Réseau de centres d'excellence MITACS (Les mathématiques des technologies de l'information et des systèmes complexes)

Les cahiers de la série scientifique (CS) visent à rendre accessibles des résultats de recherche effectuée au CIRANO afin de susciter échanges et commentaires. Ces cahiers sont écrits dans le style des publications scientifiques. Les idées et les opinions émises sont sous l'unique responsabilité des auteurs et ne représentent pas nécessairement les positions du CIRANO ou de ses partenaires.

This paper presents research carried out at CIRANO and aims at encouraging discussion and comment. The observations and viewpoints expressed are the sole responsibility of the authors. They do not necessarily represent positions of CIRANO or its partners.

\section{ISSN 1198-8177}




\title{
Dynamic Duopoly with Congestion Effects
}

\author{
Didier Laussel ${ }^{*}$, Maxime de Montmarin ${ }^{\dagger}$, Ngo Van Long ${ }^{*}$
}

\begin{abstract}
Résumé / Abstract
On étudie la concurrence entre deux firmes qui vendent des biens ou des services durables sous la condition d'encombrement. À chaque instant, des clients nouveaux achètent une unité du bien, en comparant les prix et les taux d'encombrement futur. On caractérise l'équilibre markovien de ce jeu. L'existence des externalités négatives rend la concurrence moins féroce. On montre que la firme qui a la plus grande capacité a, dans l'état stationnaire, une plus grande part de marché, un prix plus élevé, et un taux d'encombrement plus faible. Le prix du bien d'une nouvelle firme diminue continuellement, tandis que celui de son rival en exercise monte. La vitesse de convergence est une fonction croissante de l'effet d'encombrement.
\end{abstract}

Mots clés : duopole, jeux différentiels, équilibre markovien parfait.

We analyze duopolistic competition between horizontally differentiated firms selling durable goods or services subject to congestion. At each point of time, new customers buy one unit of the commodity from one of the firms, by comparing present prices and future congestion rates. We study the linear Markov equilibrium of this game which exists and is unique when firms are not too different. The existence of negative consumption externalities is shown to soften the price competition. Moreover, we show that the firm with the larger capacity has, at the steady state, a larger market share, a higher price, and a lower congestion rate. The price of an entrant decreases gradually after entry, while the price of the incumbent rises. The speed of convergence to the steady state is faster, the stronger is the congestion effect.

Keywords: duopoly, differential games, Markov perfect equilibrium.

Codes JEL : C61, D42, D92, H21, L5.

\footnotetext{
* GREQAM, Université de la Méditerranée, Château la Farge, Route des Milles, Les Milles, France. Email : Laussel@univ-aix.fr, fax: 33-4-42-93-09-68.

${ }^{\dagger}$ GREQAM, Université de la Méditerranée, Château la Farge, Route des Milles, Les Milles, France.

$\$$ CIRANO and CIREQ, Department of Economics, McGill University, 855 Sherbrooke St West, Montreal, H3A 2T7, Canada. Email : ngo.long@mcgill.ca.
} 


\section{Introduction}

In this paper we investigate the dynamic price competition between two horizontally differentiated "profit-maximizing clubs" which face at each point of time a flow of new customers who decide to belong to one club or the other on the basis of a comparison of access prices and of future congestion rates.

In the public economics literature, a club is defined as a group of people sharing a public good subject to congestion. A classical example is a swimming pool. There are many other examples of congestible resources. Among the most prominent ones are those related to communication and information based industries. It has been pointed out that as usage grows congestion affects many parts of the Internet (see Odlyzko,1999). As put by MacKie, Mason and Varian (1994a, page 1) in their exploratory paper on Internet economics: "There are many network resources whose performance suffers when there is 'overuse': the switching capacity of the routers, the bandwidth of the transport medium, the disk and CPU capacity of popular servers..."

A special class of clubs that is becoming very prevalent is the class of "profit-maximizing clubs" (Scotchmer, 1985). The distinctive features of profit-maximizing clubs are (i) they are actually profit maximizing firms, and (ii) customers have to pay an admission price in order to be allowed to share the use of a common facility. The utility which customers derive from this use is increasing in the facility's size and decreasing in the number of individuals who share the facility. With the privatization and commercialization of the Internet, the access to congestible network resources (such as a Web site, an ftp server or a router) is very often provided by competing profit-maximizing firms. These "Internet Service Providers" (ISP) are the modern examples of the "profit-maximizing clubs" analyzed by Scotchmer (1985).

We develop a highly simplified dynamic model of price competition between two profit-maximizing clubs (say, two internet service providers). In particular, we characterize the equilibrium pricing 
strategies of the firms, and study the evolution of access prices and market shares. We hope this simplified model can be used to shed light on the nature of price competition between two congestible networks that provide horizontally differentiated services, such as two web sites. Basic to our analysis is the assumption that once they have selected a firm, customers cannot instantaneously change their mind. They consequently have to take into account not only the prices and "distance" to each firm but also the anticipated future congestion rates, when they make their decision to belong to one or the other "profitmaximizing club".

Doganoglu (2000) develops a model which bears some similarities to ours: both models deal with dynamic price competition between two horizontally differentiated firms when there exist consumption externalities. There is however a very important difference. In Doganoglu's model, consumers do not look forward, and they do not forecast future externalities. In our model, consumers, in order to make a rational decision, must forecast future congestion rates. Thus, in our model, rational expectation equilibrium is a key requirement. The concept of rational expectation equilibrium plays no role in Doganoglu's model.

While there are several possible interpretations of our model, and of its assumptions, for the sake of convenience, in what follows we will stick, in the main text, to one interpretation. Other possible interpretations will be mentioned in footnotes.

We consider two firms located at the two extremities of Hotelling's linear city represented by the interval $[0,1]$. Each firm provides access to a facility of a given exogenous size. Consumers are uniformly distributed along the interval $[0,1]$. Each consumer faces a constant probability of death at each point of time. Also, at each point of time, a flow of new consumers enters the market. For simplicity, we assume the entry rate equals the death rate, so that the population is stationary.

Upon entering the market, a consumer pays (once, and for all) a subscription price to a firm of his choice. This subscription entitles him to a life-time flow of service (one unit of service per unit of time) 
from the firm, but the quality of the service is affected by consumption externalities (say, overcrowding). Also, the consumer has to bear at each point of time a quadratic travel cost in order to be able to use the facility provided by a firm. The consumer's instantaneous utility for using the facility is a decreasing function of the congestion rate of this facility, as measured by the ratio of the number of customers to the size of the facility. At each point of time the firms simultaneously choose their subscription prices for new consumers . Each firm takes into account the fact that attracting new consumers today by lowering current subscription prices will result in larger future congestion rates and hence fewer new subscribers in the future. ${ }^{1}$

The duopolistic competition is modelled here as a state-space differential game where the firms strategies and the customers expectations depend only on the "payoff-relevant state", i.e., the market shares. In other words we analyze the Markov Perfect Equilibria of our game where not only the strategies but also the expectations are Markovian (Karp,1996, and Driskill, 2001). For simplicity, we restrict our attention to Linear Markov Perfect Equilibria in which both the firms' strategies and the consumers' expectations are linear in the state variables (the market shares). The reasons for this choice of focus are two-fold. Firstly, the demand function is linear in the control variables (the prices), while the profit function is quadratic in the control variables and linear in the state variables. Our game being linearquadratic (the objective function of each firm is linear-quadratic and concave in the state and control variables, the equation of motion is linear), it is natural to search for linear equilibrium strategies. Secondly, even though it is known that in general there may exist non-linear strategies that solve linear-quadratic differential games, such strate-

\footnotetext{
${ }^{1}$ Note that a different interpretation, in which the negative consumption externalities follow from social and not technological reasons, is equally consistent with our model. In this interpretation two firms produce horizontally differentiated durable goods and consumers' behavior is characterized by vanity and subject to snob effects (for a static model along these lines see Grilo, Shy and Thisse (2001)). A fixed fraction of randomly chosen durable goods in the hands of the consumers have to be replaced at each point of time.
} 
gies are technically difficult to compute analytically. Furthermore, it is true that, in linear-quadratic problems, best replies to linear strategies are linear.

We show that, in equilibrium, other things being equal, a firm with a larger market share charges a lower price. Intuitively this is the consequence of a higher congestion rate which the customers rationally expect to prevail at this firm. When the firms are identical, i.e., when the sizes of their facilities are the same, we show that the steady-state prices are higher than what they would be if there were no congestion effects. At first this might seem counter-intuitive: congestion means lower quality, and would this not be translated into lower consumer valuation and thus lower price? Upon reflection, the higher price is due to the fact that lower quality softens competition between the duopolists. The presence of future negative consumption externalities softens duopolistic price competition. There is little incentive to cut prices in order to attract more new consumers when eveyone knows that this will result in higher future congestion rates which will render the firm less attractive for future new consumers. The other results we obtain are about the implications of different facility sizes. We show that the firm which has the larger capacity has larger steady-state market share, higher steady-state price and lower steady-state rate of congestion.

Our paper is related to a paper by Grilo, Shy and Thisse (2001) who deal, in a static framework, with price competition when consumer behavior is characterized by conformity or vanity. They analyze the case where the pleasure of consuming a good is affected for social reasons by the consumption choices of the others. When the utility from buying the good increases (respectively, decreases) with the number of the consumers they speak of "conformity" (respectively, "vanity"). In the case of vanity, the existence of negative consumption externalities softens price competition. 


\section{The model}

\subsection{Assumptions and notation}

We consider two firms located at the two extremities of the interval $[0,1]$, firm 1 at 0 and firm 2 at 1 . At time $t$, they post subscription prices $p_{1}(t)$ and $p_{2}(t)$. There is a continuum of consumers of mass 1 uniformly distributed over the interval $[0,1]$. Firm $i(=1,2)$ provides to its customers the access to its facility. The capacity $K_{i}$ of firm $i$ is fixed, for simplicity. Consumers face a constant probability of death $^{2}$ equal to $\mu$. (A non-constant probability of death would be more realistic but would overburden the analysis.) Thus, at each point of time, consumers exit the market at the rate $\mu$. We assume they are replaced by an equal flow of new consumers. The population is thus stationary. Consumers make their choice of firm only at the time they enter the market.

A consumer located at $x \in[0,1]$ bears a "travel cost" of $\tau x^{2}$ per unit of time if he chooses firm 1 , and $\tau(1-x)^{2}$ if he chooses firm 2 . This travel cost may be interpreted as a utility loss from the divergence between the type of the facility of his club and his "ideal" (most preferred) facility type. The travel cost means that the two firms provide differentiated services to the consumers. We have chosen the quadratic travel cost for tractability. An alternative specification, linear travel cost, is also tractable, but computation would be more awkward. We conjecture that the results would be much similar. (If we were to allow firms to choose locations in the interior of the interval $[0,1]$, some serious problems would arise with linear travel cost; see d' Aspremont et al. 1979.)

We assume in addition that there is a negative consumption externality. Let $D_{i}(t)$ denote the market share of firm $i$ at time $t$. The consumption externality, incurred at each point of time, is measured in monetary units by $\frac{A}{K_{i}} D_{i}(t)$ where $A$ is a negative parameter. (The limiting case where $A \stackrel{K_{i}}{=} 0$ corresponds to zero externality.) Such a

\footnotetext{
${ }^{2}$ We thank a referee for suggesting this overlapping-generations interpretation.
} 
consumption externality may represent the congestion effects, i.e., the quality of the service decreases with the number of users. For example, the greater the number of customers who log in, the slower the connection. We specify that a consumer's utility decreases linearly with increased rate of congestion. (The linearity assumed here does not seem inappropriate for internet traffic, though it would be highly inappropriate for highway traffic.) For a same number of customers, one incurs a lower utility loss by choosing a firm with a larger capacity. In the following for notational simplicity we define $a_{i}=\frac{A}{K_{i}}$. (Note that $a$ is negative.) We call $a_{i}$ firm $i$ 's congestion coefficient, and $a_{i} D_{i}(t) / A$ its congestion rate at time $t$. In our model, both $a_{1}$ and $a_{2}$ are exogenous.

It is convenient to define $a_{\min }$ as the smaller (i.e., the more negative) of the two negative numbers $a_{1}$ and $a_{2}$ :

$$
a_{\min }=\min \left\{a_{1}, a_{2}\right\}<0
$$

The average congestion coefficient is defined as

$$
a=\frac{a_{1}+a_{2}}{2}<0
$$

As we shall see, it turns out that a number of equilibium parameters depend on $a$ (and not on $a_{1}$ and $a_{2}$ separately).

\subsection{Consumer's choice and market demand}

Let $x_{i}$ denote the location of firm $i$. Since we assumed the two firms are located at the two extremities, it follows that $x_{1}=0$ and $x_{2}=1$. Let $r>0$ be the discount rate. For a consumer located at $x$ who enters the market at time $t$, his life-time utility from being a customer of firm $i$ (net of congestion cost and transportation cost) is

$$
W_{i}(x, t)=\int_{t}^{\infty}\left[U+a_{i} D_{i}(v)-\tau\left(x-x_{i}\right)^{2}\right] e^{-(r+\mu)(v-t)} d v
$$

where $U$ is the utility per unit of time from consuming one unit of the service if congestion and transport cost are both zero. The sum $r+\mu$ is called the effective discount rate. 
His life-time surplus if he chooses firm $i$ is

$$
V_{i}(x, t)=W_{i}(x, t)-p_{i}(t)
$$

The consumer compares $V_{i}(x, t)$ with $V_{j}(x, t)$ and subscribes to the firm that gives the greater life-time surplus, if it is non-negative. (If it is negative, the consumer will subscribe to neither firm.)

Since both $D_{i}$ and $\left(x-x_{i}\right)^{2}$ are bounded above by 1 , and $a_{\min } \leq$ $a_{i}<0$, it follows that

$$
W_{i}(x, t) \geq \frac{U+a_{\min }-\tau}{r+\mu} .
$$

We assume that $U$ is sufficiently large, as specified below:

\section{Assumption 1:}

$$
\frac{U+a_{\min }-\tau}{r+\mu}>0
$$

This assumption implies that for given population size, the sum of congestion cost and travel cost is not high enough to deter consumers from patronizing either firm. It is a standard assumption in Hotelling models of horizontal differentiation (see d'Aspremont, Gabszewicz and Thisse, 1979, for instance). It rules out the not very interesting case where each firm would be a local monopolist.

Let us define the lifetime congestion at firm $i$ for the new consumers at $t$ as

$$
\Lambda_{i}(t)=\int_{t}^{\infty} D_{i}(v) e^{-(r+\mu)(v-t)} d v \geq 0
$$

This expression, when multiplied by $a_{i}<0$, represents the discounted value of the future stream of congestion externalities that the consumer will experience at firm $i$ from time $t$ onwards. Note that $\Lambda_{i}(t)$ has two important properties: first, $\Lambda_{i}(t) \in\left[0, \frac{1}{r+\mu}\right]$ because $D_{i}(t) \in[0,1]$, and second, $\Lambda_{1}(t)+\Lambda_{2}(t)=\frac{1}{r+\mu}$, because $D_{1}(t)+D_{2}(t)=1$. We assume 
that consumer expectations are rational. It is as if the consumer could perfectly forecast the future time path of congestion at each firm.

Equation (4) can then be more conveniently written as

$$
V_{i}(x, t)=\frac{U-\tau\left(x-x_{i}\right)^{2}}{r+\mu}+a_{i} \Lambda_{i}(t)-p_{i}(t)
$$

Thus, at time $t$ a new consumer located at $x$ will find that choosing firm $i$ is optimal if

$$
a_{1} \Lambda_{1}(t)-p_{1}(t)-\frac{\tau x^{2}}{r+\mu} \geq a_{2} \Lambda_{2}(t)-p_{2}(t)-\frac{\tau(x-1)^{2}}{r+\mu}
$$

and choosing firm 2 is optimal if the inequality is reversed. If $x$ is such that (8) holds with equality, the consumer will be indifferent between the two firms.

For given $p_{1}(t), p_{2}(t), \Lambda_{1}(t)$, since $\Lambda_{2}(t)=\frac{1}{r+\mu}-\Lambda_{1}(t)$, there exists a unique number $\widetilde{x}(t)=\widetilde{x}\left(p_{1}(t), p_{2}(t), \Lambda_{1}(t)\right)$ such that expression $(8)$ holds with equality if and only if $x$ takes the value $\widetilde{x}(t)$, where

$$
\widetilde{x}(t)=\left[\frac{1}{2}+\frac{\left(p_{2}(t)-p_{1}(t)\right)(r+\mu)+2 a \Lambda_{1}(t)(r+\mu)-a_{2}}{2 \tau}\right]
$$

where $a$ is given by (2).

Thus if $\widetilde{x}(t) \in[0,1]$ then new consumers at time $t$ who are located to the left of $\widetilde{x}(t)$ will choose firm 1 and those who are located to the right of $\widetilde{x}(t)$ will choose firm 2 . (If $\widetilde{x}(t)<0$, then all new consumers at time $t$ will choose firm 2 , and if $\widetilde{x}(t)>1$ then all new consumers will choose firm 1.) It is easy to see that

$$
-\tau \leq\left(p_{2}(t)-p_{1}(t)\right)(r+\mu)+2 a \Lambda_{1}(t)(r+\mu)-a_{2} \leq \tau
$$

Recalling that the rate of flow of new consumers is $\mu$, it follows that the rate of new subscriptions to firm 1 is $d_{1}(t)=\mu \widetilde{x}(t)$ and, for firm $2, d_{2}(t)=\mu[1-\widetilde{x}(t)]$, provided that $\widetilde{x}(t) \in[0,1]$, i.e., provided 
that (9) holds ${ }^{3}$. Note that $d_{1}(t)+d_{2}(t)=\mu$ which is equal to the flow of new consumers (since the total population is normalized at unity).

Intuitively, no firm will have an incentive to set its price such that $\widetilde{x}(t)<0$ or $\widetilde{x}(t)>1$. So it is reasonable to assume that (9) holds along the equilibrium path. Then the instantaneous demand $d_{i}(t)$ to firm $i$ is ${ }^{4}$

$$
d_{i}(t)=\mu\left[\frac{1}{2}+\frac{\left(p_{j}(t)-p_{i}(t)\right)(r+\mu)+2 a \Lambda_{i}(t)(r+\mu)-a_{j}}{2 \tau}\right]
$$

where $i, j=1,2, \quad i \neq j$.

The net rate of change in the market share $D_{i}$ of firm $i$ consists of the flow of new subscriptions minus the exit flow $\mu D_{i}$ :

$$
\frac{d D_{i}(t)}{d t}=d_{i}(t)-\mu D_{i}(t)
$$

Let $k_{i}$ be the firm $i$ 's cost of servicing a customer. Then firm $i$ 's net cash flow at time $t$ is

$$
\pi_{i}(t)=p_{i}(t) d_{i}(t)-k_{i} D_{i}(t)
$$

The firms compete over an infinite horizon. Firm $i$ chooses the time path of price $p_{i}(t)$ to maximize its present value $W_{i}=\int_{0}^{\infty} \pi_{i}(t) e^{-r t} d t$. In what follows, we assume $k_{1}=k_{2}=k=0$ for simplicity. The basic results would remain unchanged if $k>0$.

\footnotetext{
${ }^{3}$ If condition (9) does not hold, then we have to deal with an instantaneous market where all new subscribers strictly prefer the same firm, say firm $i$. This cannot happens for optimizing firms, because firm $i$ could improve its profit by raising $p_{i}(t)$.

${ }^{4}$ If we wish to be completely general, we could proceed as follows. Given the set $S=\{0,1, \widetilde{x}\}$, define mid $\{0,1, \widetilde{x}\}$ to be $\widetilde{x}$ if $\widetilde{x} \in[0,1]$, to be 0 if $\widetilde{x}<0$, and to be 1 if $\widetilde{x}>1$. Then the flow demand facing firm 1 is $d_{1}(t)=\mu$ mid $\{0,1, \widetilde{x}(t)\}$ and that facing firm 2 is $d_{2}(t)=\mu-d_{1}(t)$.In what follows, we shall ignore this complication.
} 


\section{Equilibrium expectations and strategies}

We consider here the Markov Perfect Equilibria (MPE) of our game. The concept of Markov Perfect Equilibrium has several merits. We refer the readers to Fudenberg and Tirole (1991, sections 4.7 and 13.1) and Dockner et al. (2000) for fuller discussions of these merits. At these equilibria the strategies of the firms and the consumers expectations depend only on the payoff relevant information, i.e., on the physical state of the world. We begin by defining the concepts of Markov Expectation Rules for consumers, and Markov Pricing Strategies for firms. Unless otherwise indicated, all proofs are relegated to the Appendix.

\subsection{Markov Expectation Rules}

Recall that each new consumer at time $t$ must compare the lifetime surplus if he subscribes to firm 1 with the lifetime surplus if he subscribes to firm 2. In general, consumers form their expectations $\Lambda_{1}^{e}(t)$ and $\Lambda_{2}^{e}(t)$ of the actual values $\Lambda_{1}(t)$ and $\Lambda_{2}(t)$. Expectations are said to be rational if $\Lambda_{i}^{e}(t)=\Lambda_{i}(t)$.

A Markov Expectation Rule is a pair of functions $\left(F_{1}(),. F_{2}().\right)$ that generate the values $\Lambda_{1}^{e}(t)$ and $\Lambda_{2}^{e}(t)$ from what the consumer currently observes, namely the market shares $D_{1}(t)$ and $D_{2}(t)$. This pair of functions maps any observed point $\left(D_{1}(t), D_{2}(t)\right)$ on the unit simplex

$$
\Delta=\left\{\left(D_{1}(t), D_{2}(t)\right) \mid 0 \leq D_{i}(t) \leq 1, D_{1}(t)+D_{2}(t)=1\right\}
$$

to a point $\left(\Lambda_{1}^{e}(t), \Lambda_{2}^{e}(t)\right)$. Thus

$$
\Lambda_{i}^{e}(t)=F_{i}\left(D_{1}(t), D_{2}(t)\right)
$$

Since $D_{1}=1-D_{2}$, we can write

$$
\Lambda_{i}^{e}(t)=f_{i}\left(D_{i}\right)
$$

In what follows, to sharpen our focus, we assume that all consumers use the same expectation rule. Introducing heterogeneity in expectation rules could be interesting, but is beyond the scope of this paper. 
In the special case where the expectation rule is linear, we obtain the following Lemma:

Lemma 1: Linear Markov Expectation Rules that are rational must be of the form

$$
\Lambda_{i}^{e}(t)=\delta_{i}+b_{i} D_{i}(t) \equiv f_{i}\left(D_{i}(t)\right) \text { for } i=1,2
$$

where

$$
\begin{aligned}
& 0 \leq \delta_{i} \leq \frac{1}{r+\mu}-b \\
& b_{1}=b_{2}=b>0 \\
& b=\frac{1}{r+\mu}-\left(\delta_{1}+\delta_{2}\right)
\end{aligned}
$$

Remark: Lemma 1 implies that, under rational expectations, consumers extrapolate from current market shares: the higher a firm's current market share, the greater is the expected life-time congestion rate at that firm's facility.

\subsection{Markov Pricing Strategies}

A pricing strategy for firm $i$ is said to be Markovian if it is a rule which tells firm $i$ what price to charge at time $t$, based only on the knowledge of its current market share $D_{i}(t)$ and the current market share of the other firm. We denote a Markov pricing strategy by $P_{i}($.$) .$ It is a function that maps any observed point $\left(D_{1}(t), D_{2}(t)\right)$ on the unit simplex $\Delta$ to a point $p_{i}(t)$ on the real number line. Thus

$$
P_{i}\left(D_{1}(t), D_{2}(t)\right)=p_{i}(t)
$$

Again, since $D_{1}+D_{2}=1$, we can write

$$
P_{j}\left(D_{i}, D_{j}\right)=P_{j}\left(1-D_{j}, D_{j}\right) \equiv \widetilde{p}_{j}\left(D_{j}\right) \equiv \widetilde{p}_{j}\left(1-D_{i}\right)
$$


Given a pricing strategy $\widetilde{p}_{j}\left(1-D_{i}\right)$ adopted by firm $j$, and given an expectation rule $\left(f_{i}\left(D_{i}\right), f_{j}\left(D_{j}\right)\right)$ adopted by all consumers, a pricing strategy $\widetilde{p}_{i}^{*}\left(D_{i}\right)$ is said to be firm $i$ 's best reply to both the pricing strategy $\widetilde{p}_{j}($.$) and the expectation rule \left(f_{i}(),. f_{j}().\right)$, if for any initial market share $D_{i}(0)$ this pricing strategy yields a time path $p_{i}(t)$ that solves the optimal control problem

$$
\max _{p_{i}(t)} \int_{0}^{\infty} e^{-r t} \pi_{i}(t) d t
$$

subject to

$$
\begin{gathered}
\dot{D}_{i}(t)=d_{i}(t)-\mu D_{i}(t) \\
0 \leq D_{i}(t) \leq 1
\end{gathered}
$$

where

$$
d_{i}(t)=\mu\left\{\frac{1}{2}+\frac{\left[\widetilde{p}_{j}\left(1-D_{i}(t)\right)-p_{i}(t)\right](r+\mu)+2 a f_{i}\left(D_{i}(t)\right)(r+\mu)-a_{j}}{2 \tau}\right\}
$$

and $\pi_{i}(t)=p_{i}(t) d_{i}(t)$

Definition 1 A Markov perfect equilibrium is a quadruple of functions $\left(\widetilde{p}_{1}^{*}(),. \widetilde{p}_{2}^{*}(),. f_{1}(),. f_{2}().\right)$ such that $(i) \widetilde{p}_{i}^{*}($.$) is firm i$ 's best reply to both the pricing strategy $\widetilde{p}_{j}($.$) and the expectation rule \left(f_{i}(),. f_{j}().\right)$,for $i, j=1,2, i \neq j$, and (ii) expectations are rational in the sense that, for $i=1,2$,

$$
f_{i}\left(D_{i}(t)\right) \equiv \int_{t}^{\infty} D_{i}(v) e^{-(r+\mu)(v-t)} d v
$$

where

$$
\frac{d D_{i}(t)}{d t}=d_{i}(t)-\mu D_{i}(t)
$$

with $d_{i}(t)$ given by (18). 
In what follows, we will focus on Linear Markov Perfect Equilibria (LMPE) of our game, i.e., Markov perfect equilibria where the firms' strategies and the consumers' expectation functions are linear and autonomous. The reasons for this choice have been explained in the introduction.

The linear Markov pricing strategies will be written in the form

$$
p_{j}(t)=\widetilde{p}_{j}\left(D_{j}(t)\right)=\alpha_{j}+s_{j} D_{j}(t)
$$

In what follows, we solve for the constants $b, \delta_{j}, \alpha_{j}$ and $s_{j}$ for $j=1,2$.

\subsection{The optimal control problem of each firm}

Each firm $i$ has to solve the optimal control problem (17), given the strategy $\widetilde{p}_{j}\left(1-D_{i}\right), j \neq i$, and the expectation rule $\left(f_{i}\left(D_{i}\right), f_{j}\left(D_{j}\right)\right)$. Here, we focus on the case where firm i's rival follows a linear Markov pricing strategy, given by (20) and the consumer expectation rule is linear. Thus we face a standard infinite horizon optimal control problem with a linear-quadratic structure ${ }^{5}$. Introducing the current-value co-state variable $\lambda_{i}(t)$ we define the current-value Hamiltonian for firm $i$ as

$$
H_{i}(t)=\left(p_{i}(t)+\lambda_{i}(t)\right) d_{i}\left(p_{i}(t), D_{i}(t)\right)-\mu \lambda_{i}(t) D_{i}(t)
$$

where

$$
\begin{gathered}
d_{i}\left(p_{i}(t), D_{i}(t)\right)= \\
\mu\left\{\frac{1}{2}+\frac{\left[\alpha_{j}+s_{j}\left(1-D_{i}(t)\right)-p_{i}(t)\right](r+\mu)+2 a\left[\delta_{i}+b D_{i}(t)\right](r+\mu)-a_{j}}{2 \tau}\right\} .
\end{gathered}
$$

The necessary conditions include:

$$
\lambda_{i}(t)=\frac{\tau-a_{j}}{r+\mu}+\alpha_{j}+s_{j}\left(1-D_{i}(t)\right)-2 p_{i}(t)+2 a\left[\delta_{i}+b D_{i}(t)\right]
$$

\footnotetext{
${ }^{5}$ For theorems stating necessary and sufficient conditions, see, for example, Leonard and Long (1992, Chapter 9). Alternative sufficient conditions are given in Dockner et al. (2000, Section 3.6).
} 


$$
\frac{d \lambda_{i}(t)}{d t}=(r+\mu) \lambda_{i}(t)-\left[p_{i}(t)+\lambda_{i}(t)\right] \frac{\mu(r+\mu)}{2 \tau}\left(2 a b-s_{j}\right)
$$

A similar set of equations is obtained from firm $j$ 's optimal control problem. Using these two set of equations, we get the following lemma:

Lemma 2: (Equilibrium requirements for firms, given the consumer's parameters $\delta_{1}, \delta_{2}$ and $b$ )

Given $b, \delta_{1}$ and $\delta_{2}$ of the consumers expectation rule, any pair of linear pricing strategies $\widetilde{p}_{i}\left(D_{i}\right)=\alpha_{i}+s_{i} D_{i}$ that solve the optimization problem of the firms must have the following properties (i) $s_{1}=s_{2}=s$, where s satisfies the equation

$$
2 a b[(r+2 \mu) \tau-2 a b \mu(r+\mu)]+s[8 a b \mu(r+\mu)-3(r+2 \mu)]-4 \mu(r+\mu) s^{2}=0(
$$

and (ii) $\alpha_{1}$ and $\alpha_{2}$ satisfy the two equations

$$
[\tau-2 \mu(a b-s)]\left[\left(s+\alpha_{j}+2 a \delta_{i}\right)(r+\mu)-a_{j}\right]-2(r+\mu)[\tau-\mu(a b-s)] \alpha_{i}=0(24)
$$

for $i=1,2, i \neq j$.

Remark: It is interesting that $s_{1}=s_{2}$ even when the firms have different capacities.

\subsection{Equilibrium Linear Markov Expectation Rule}

We now show that the requirement that expectations be rational implies certain restrictions on the constants $\delta_{1}, \delta_{2}$ and $b$ of the linear expectation rule. We obtain the following result:

Lemma 3: (Equilibrium requirements for consumers, given the firms parameters $\alpha_{1}, \alpha_{2}$ and $s$

Given $\alpha_{1}, \alpha_{2}$ and $s$, the rational expectation requirement that $\Lambda_{i}^{e}(t)=\Lambda_{i}(t)$ can be satisfied by a linear expectation rule if and only if the constants $\delta_{i}$ and $b$ satisfy the following equations. For $b$ :

$$
-\left(b r \tau-\tau+b r s \mu+2 b \tau \mu+b s \mu^{2}\right)+a b^{2} \mu(r+\mu)=0
$$


For $\delta_{i}$ :

$$
\delta_{i}=\frac{b \mu\left(r s+\tau+s \mu-a_{j}+(r+\mu)\left(\alpha_{j}-\alpha_{i}\right)\right)}{2(r+\mu)(a b \mu-\tau)}, i, j=1,2, i \neq j(26)
$$

A direct implication of Lemmas 2 and 3 is

\section{Lemma 4: (Difference in intercepts of the pricing strate- gies)}

Under rational expectations and linear strategies, differences in capacities are reflected in differences in the intercepts of the pricing strategies.

\section{Proof:}

Using equations (26) and subtracting $\delta_{2}$ from $\delta_{1}$ one obtains

$$
\delta_{1}-\delta_{2}=\frac{b \mu\left[a_{1}-a_{2}-2(r+\mu)\left(\alpha_{1}-\alpha_{2}\right)\right]}{2(r+\mu)(\tau-a b \mu)}
$$

Subtracting the second equation (24) from the first and substituting the right-hand side of (27) for $\delta_{1}-\delta_{2}$ in the resulting equation, we obtain:

$$
\alpha_{1}-\alpha_{2}=-\frac{[\tau+2(s-a b) \mu]\left(a_{1}-a_{2}\right)}{(r+\mu)(-3 \tau+5 a b \mu-4 s \mu)}
$$

Remark: It follows that, under rational expectations, the two firms's linear equilibrium strategies are identical (i.e., $p_{i}=\alpha+s D_{i}$ ) if and only if their capacities $K_{1}$ and $K_{2}$ are identical (so that $a_{1}=a_{2}$ ). The same condition is necessary and sufficient for the equality $\delta_{1}=\delta_{2}$.

\subsection{A Complete Characterization of Linear Markov Perfect Equilib- rium}

We now solve for a Linear Markov Perfect Equilibrium. To do so, we use the six equations (23), (24), (25), (26), to solve for the six unknowns, $b, s, \alpha_{1}, \alpha_{2}, \delta_{1}$ and $\delta_{2}$. It turns out that the equations can be 
solved sequentially. First, the two equations (23) and (25) determine $b^{*}$ and $s^{*}$, and their values are dependent on the average congestion coefficient $a$ (not on the individual $a_{1}$ and $a_{2}$ ). Second, $\alpha_{1}^{*}, \alpha_{2}^{*}, \delta_{1}^{*}$ and $\delta_{2}^{*}$ are dependent on $b^{*}$ but not on $s^{*}$.

Lemma 5: The equilibrium value $b^{*}$ is unique, and has the following properties: (i) it is the unique solution in the interval $\left(0, \frac{1}{r+\mu}\right)$ of the cubic polynomial

$$
8 \tau-10 b \tau(r+2 \mu)+2 b^{2} \tau(r+2 \mu)^{2}+2 a b^{3} \mu\left(r^{2}+3 r \mu+2 \mu^{2}\right)=0(29)
$$

and (ii) $b^{*} \leq \frac{1}{r+2 \mu}$.

The equilibrium value $s^{*}$ is

$$
s^{*}=s\left(b^{*}\right)=\frac{-2 \tau\left(-1+b^{*} r+2 b^{*} \mu\right)+2 a b^{* 2} \mu(r+\mu)}{2 b^{*} \mu(r+\mu)}<0
$$

Thus, in a LMPE, the higher is the current market share $D_{i}(t)$, the lower is the current price $p_{i}(t)$.

It remains to solve for $\alpha_{1}^{*}, \alpha_{2}^{*}, \delta_{1}^{*}$ and $\delta_{2}^{*}$. Recall that Lemma 1 states that $\delta_{1}$ and $\delta_{2}$ must be positive. It turns out that this property can be satisfied in a LMPE if and only if the difference between the capacities of the two firms is bounded, in absolute value, by a term that depends on the average congestion rate $a$. This will be made precise by the following assumptions.

Assumption 2: The absolute value of the difference between $a_{1}$ and $a_{2}$ does not exceed $\omega$, wherewhere

$$
\omega \equiv\left[1-b^{*}(r+\mu)\right]\left[\frac{\tau\left[4-b^{*}(r+5 \mu)\right]}{2 \mu(r+\mu) b^{* 2}}-2 a\right]
$$

Remark: $\omega>0$ because of part (ii) of lemma 5. Assumption 2 implies

$$
a_{2} \leq a_{1}+\omega
$$


and

$$
a_{1} \leq a_{2}+\omega
$$

Inequality (32) states that the negative number $a_{2}$ is algebraically smaller than the sum of $\omega$ and the negative number $a_{1}$. It is is satisfied if either (i) $a_{1}$ is closer to zero than $a_{2}$, or (ii) $a_{1}$ is more negative than $a_{2}$ but not substantially so. It will be seen that (32) is necessary and sufficient for $\delta_{1}^{*}>0$. Similarly, for $\delta_{2}^{*}>0$, we need inequality (33).

Proposition 1 Under assumptions $1 A$ and $1 B$, there is a unique Linear Markov Perfect Equilibrium. It has the following properties:

1. The rational expectation rule is $f_{i}\left(D_{i}\right)=\delta_{i}^{*}+b^{*} D_{i}, i=1,2$, where $b^{*}$ is given in Lemma 5, and where $\delta_{i}^{*}=\delta_{i}\left(b^{*}\right)>0$, and

$$
\delta_{i}(b)=\frac{1-b(r+\mu)}{2(r+\mu)}-\frac{b^{2} \mu\left(a_{i}-a_{j}\right)}{4 a b^{2} \mu(r+\mu)+4 \tau(-4+b(r+5 \mu))}
$$

2. The pricing strategies are $p_{i}=\alpha_{i}^{*}+s^{*} D_{i}, i=1,2$, where $s^{*}<0$ and is given in Lemma 5 , and where $\alpha_{i}^{*}=\alpha_{i}\left(b^{*}\right)$, and

$$
\alpha_{i}(b)=H(b)+K(b)\left(a_{i}-a_{j}\right)
$$

where $H(b)=\tau \frac{2-b(3 r+5 \mu)+b^{2}(r+\mu)(r+3 \mu)}{b^{2} \mu(r+\mu)^{2}}$ and $K(b)=\frac{-\tau(2-b(r+3 \mu))}{2(r+\mu)\left[a b^{2}(r+\mu)+(b(r+5 \mu)-4) \tau\right]}$ and $H\left(b^{*}\right)>0, K\left(b^{*}\right)>0$.

Remark: Conditions (32) and (33) which are equivalent to $\delta_{i} \geq 0$, $i=1 ; 2$ (see condition (14)), mean simply that for the existence of a LMPE the difference between the capacity levels of the two firms should not be too great. This condition is trivially satisfied in the symmetric case when $a_{1}=a_{2}$. When conditions (32) and (33) are not satisfied, there does not exist a linear MPE. In that case, it is an open 
question whether there exists a non-linear MPE, possibly such that the firm with the larger capacity becomes a monopolist in finite time.

The equilibrium strategies of both firms are such that they reduce their prices as their market shares increase (this is the meaning of $\left.s^{*}<0\right)$. The highest price a given firm $i$ will set is the price which it will choose just after entering the market, when its stock of customers $D_{i}$ is zero. This follows intuitively from the negative consumption externality which we assume. New customers rationaly expect that the entrant will for a while offer a better service (i.e, a lower congestion rate) than the incumbent. This allows the entrant to set initially high prices. After entry, the price of the entrant will steadily decrease while the price of the incumbent will steadily increase as the market shares and the congestion rates tend toward their steady state values.

If originally, there is only one firm in a monopoly steady state equilibrium, the unexpected entry of a new firm will cause the price of the incumbent to jump down from its steady state value, and afterward his price will rise steadily; thus there is an overshooting. Regarding the fixed component of the firms' price strategies, namely the $\alpha_{i} \mathrm{~s}$, it is worth noting that they are always strictly positive in the symmetric case when $a_{1}=a_{2}$, i.e., when the capacities $K_{1}$ and $K_{2}$ of the firms are equal. In such a case dumping (i.e., setting its price $p_{i}$ below its marginal cost) is not optimal for a new entrant. However it may be optimal for an incumbent $i$ which initially covers all the market (i.e. $D_{i}=1$ ) to set a price below marginal cost immediately after the entry of a competitor. This should not be seen as an entry deterrence strategy, but rather as the consequence of a very high initial congestion rate, relative to that of the new entrant, which makes the incumbent unattractive from the customers' viewpoint.

Proposition 2 When the firms have identical capacities (i.e,. $a_{1}=$ $\left.a_{2}=a\right)$ the steady state prices in the unique Linear Markov Perfect Equilibrium are given by

$$
\widehat{p}_{i}=\frac{a b^{* 3} \mu(r+\mu)^{2}+\tau\left[4-b^{*}(5 r+9 \mu)+b^{* 2}(r+\mu)(r+4 \mu)\right]}{2 b^{* 2} \mu(r+\mu)^{2}}(36)
$$


Moreover $\widehat{p}_{i}>\frac{\tau}{r+\mu}>0$.

It is very easy to see that $\widehat{p}_{i} \rightarrow \frac{\tau}{r+\mu}$ as $a \rightarrow 0^{6}$. This result means that without the negative consumption externality, i.e., in the absence of congestion effects, the firms would charge steady-state prices equal to four times the present value of the travel cost of the marginal consumer (located at distance 1/2):

$$
\widehat{p}_{i}=(4) \frac{\tau(1 / 2)^{2}}{r+\mu}
$$

The introduction of negative consumption externalities increases the equilibrium price above this value. The competition between firms in the presence of congestion effects is less intense than what would prevail in the absence of such negative consumption externalities. The fact that customers value negatively the present and future market share of a firm does indeed lead to a softening of competition. The intuition behind this result is as follows. The firms themselves value less their present and future market shares since congestion would prevent them from posting high prices in the future. Consequently they have less incentive to cut present prices in an attempt to attract more new customers. It is rather clear that positive consumption externalities would have the opposite effect.

A somewhat surprising implication of this result is as follows. Suppose that initially the firms have $K_{1}=K_{2}=\infty$, so that $a_{1}=a_{2}=0$, and $\widehat{p}_{i}=\frac{\tau}{r+\mu}$. Then the firms have an incentive to collude on an equal reduction of their capacities, because this would result in strictly negative $a_{i}$ and $a_{j}$, and consequently higher prices and higher profits.

Proposition 3 below gives some results on the differences between firms' strategies in the case where firms' capacities differ. We denote by a hat the steady state values of the variables.

\footnotetext{
${ }^{6}$ From equation $(29) b^{*} \rightarrow \frac{1}{r+2 \mu}$ as $a \rightarrow 0$.
} 
Proposition 3 In the unique Linear Markov Perfect Equilibrium the firm with the larger capacity

1. has the greater $\alpha$, i.e.

$$
\alpha_{1}-\alpha_{2}=2 K\left(b^{*}\right)\left(a_{1}-a_{2}\right)
$$

where $K\left(b^{*}\right)>0$

2. has the larger steady state market-share, i.e.,

$$
\widehat{D}_{1}-\widehat{D}_{2}=Z\left(b^{*}\right)\left(a_{1}-a_{2}\right)
$$

where $Z(b)=\frac{b^{2} \mu(r+\mu)}{(-1+b(r+\mu))\left(a b^{2} \mu(r+\mu)+4 \tau(-4+b(r+5 \mu))\right)}$ and $Z\left(b^{*}\right)>0$.

3. has the higher steady state price

$$
\widehat{p}_{1}-\widehat{p}_{2}=W\left(b^{*}\right)\left(a_{1}-a_{2}\right)
$$

where $W(b)=\frac{a b^{3} \mu(r+\mu)^{2}+\tau\left(4-b(5 r+9 \mu)+b^{2}(r+\mu)(r+4 \mu)\right)}{2(r+\mu)(-1+b(r+\mu))\left(a b^{2} \mu(r+\mu)+4 \tau(-4+b(r+5 \mu))\right)}$ and $W\left(b^{*}\right)>$ 0 .

4. has the lower steady state rate of congestion, i.e.

$$
\widehat{c}_{1}-\widehat{c}_{2}=U\left(b^{*}\right)\left(a_{1}-a_{2}\right)
$$

where $U(b)=\frac{1}{A(r+2 \mu)}\left(\frac{\mu \tau\left(4-4 b(r+2 \mu)+3 b^{2}(r+\mu)(r+2 \mu)\right)}{4(-1+b(r+\mu))\left(a b^{2} \mu(r+\mu)+4 \tau(-4+b(r+5 \mu))\right.}\right)$ and $U\left(b^{*}\right)<$ 0 .

All these results are intuitive: a firm with a larger capacity has a larger market share but nevertheless a lower rate of congestion which allows it to set a higher price. 
Our final proposition below, the proof of which is straightforward, states that the rate convergence to the steady state is faster, the more important are the congestion effects, i.e., the greater is the absolute value of $a$. This means that in a market where there is congestion, the entrant's market share increases more quickly than in a market without congestion effects. This result has as its parallel a result in Doganoglu (2000) in a model without rational expectations, according to which positive consumption externalities slow down convergence toward the steady state.

Proposition 4 At the unique Linear Markov Perfect Equilibrium the market share of firm $i$ evolves according to

$$
D_{i}(t)=\left(D_{i}(0)-\frac{\delta_{i}\left(b^{*}\right)(r+\mu)}{1-b^{*}(r+\mu)}\right) e^{\left(r+\mu-\frac{1}{b^{*}}\right) t}+\frac{\delta_{i}\left(b^{*}\right)(r+\mu)}{1-b^{*}(r+\mu)}
$$

where $\delta_{i}(b)$ is given by equation (34). The rate of convergence to the steady state market share $\widehat{D}_{i}=\frac{\delta_{i}\left(b^{*}\right)(r+\mu)}{1-b^{*}(r+\mu)}$ is equal to $\frac{1}{b^{*}}-(r+$ $\mu$ ) and is decreasing in $b^{*}$. From equation (29) $b^{*}$ is increasing in $\frac{a}{\tau}$ : convergence to the steady state is faster, the more important are the congestion effects (a has a bigger absolute value) and the more differentiated are the products ( $\tau$ is larger).

\section{Concluding remarks}

By setting up a model of dynamic oligopolistic competition with differentiated products involving congestion externalities, we have been able to obtain a number of predictions. For example, we showed how, upon the entry of a new firm, an incumbent would subtantially cut his price from the monopoly price, and let it rise again gradually, to a lower steady tate level. Such an overshooting reaction is not an entrydeterrence strategy. Rather, it is a subgame perfect best response to the linear Markovian strategy of the entrant. Our model also shows that competition is softer, the greater is the congestion effect. This 
suggests that if firms can collude on capacity choices, they will choose smaller capacities (even if the marginal cost of capacity is zero). This is in keeping with the standard theoretical result that market power leads to the underprovision of goods.

Several extensions of the model seem feasible and worthwhile. A natural extension is the endogenisation of capacities. Another extension would be to allow existing consumers to switch brands, in response to price incentives. A third extension would be to endogenize the number of firms.

Acknowledgements: We would like to thank Hassan Benchekroun, Kim Long, and Koji Shimomura for discussions and comments. 


\section{Appendix}

\section{Proof of Lemma 1}

Since the actual values $\Lambda_{i}(t)$ are defined by (6), for rational expectations to hold, we require that the functions $F_{i}($.$) satisfy the following$ properties

$$
\begin{aligned}
& 0 \leq F_{i}\left(D_{1}(t), D_{2}(t)\right) \leq \frac{1}{r+\mu} \\
& F_{1}\left(D_{1}(t), D_{2}(t)\right)+F_{2}\left(D_{1}(t), D_{2}(t)\right)=\frac{1}{r+\mu}
\end{aligned}
$$

for all $\left(D_{1}(t), D_{2}(t)\right) \in \Delta$.

Since there are only two firms, condition (42) implies that once the function $F_{1}($.$) is specified, we can infer the function F_{2}($.$) because of$ the functional dependence. Also, since $D_{2}=1-D_{1}$, we can write

$$
\Lambda_{1}^{e}(t)=F_{1}\left(D_{1}(t), D_{2}(t)\right)=F_{1}\left(D_{1}(t), 1-D_{1}(t)\right) \equiv f_{1}\left(D_{1}(t)\right)
$$

and

$\Lambda_{2}^{e}(t)=\frac{1}{r+\mu}-F_{1}\left(D_{1}(t), D_{2}(t)\right)=\frac{1}{r+\mu}-f_{1}\left(D_{1}(t)\right)=\frac{1}{r+\mu}-f_{1}\left(1-D_{2}(t)\right) \equiv f_{2}\left(D_{2}(t)\right)$

Rational expectations mean $\Lambda_{i}^{e}(t)$ is equal to $\Lambda_{i}(t)$, i.e., for all $t$,

$$
\Lambda_{i}^{e}(t)=f_{i}\left(D_{i}(t)\right)=\int_{t}^{\infty} D_{i}(v) e^{-(r+\mu)(v-t)} d v \equiv \Lambda_{i}(t)
$$

The special case of interest is the linear expectation rule, where, for $D_{1} \in[0,1]$

$$
0 \leq f_{1}\left(D_{1}\right)=\delta_{1}+b_{1} D_{1} \leq \frac{1}{r+\mu}
$$

and, for $D_{2} \in[0,1]$

$f_{2}\left(D_{2}\right)=\frac{1}{r+\mu}-f_{1}\left(1-D_{2}(t)\right)=\frac{1}{r+\mu}-\left[\delta_{1}+b_{1}\left(1-D_{2}\right)\right] \equiv \delta_{2}+b_{2} D_{2}$ 
It follows that $b_{2}=b_{1} \equiv b$ and $\delta_{2}=\frac{1}{r+\mu}-b-\delta_{1}$.Then, setting $D_{1}=0$ in (44), we obtain the restriction

$$
0 \leq \delta_{1} \leq \frac{1}{r+\mu}
$$

and, setting $D_{1}=1$ in (44), we obtain

$$
0 \leq \delta_{1}+b \leq \frac{1}{r+\mu}
$$

which yields the restriction

$$
b \leq \frac{1}{r+\mu}-\delta_{1} \leq \frac{1}{r+\mu}
$$

Furthermore, the rational expectations requirement that $\Lambda_{i}^{e}(t)=\Lambda_{i}(t)$ implies the restriction that $b \geq 0$. To see this, note that $\Lambda_{i}^{e}(t)=\Lambda_{i}(t)$ implies

$$
\dot{\Lambda}_{i}^{e}(t)=\dot{\Lambda}_{i}(t)
$$

which implies, from differentiating (43) with respect to time,

$b \dot{D}_{i}(t)=(r+\mu) \Lambda_{i}(t)-D_{i}(t)=(r+\mu) \Lambda_{i}^{e}(t)-D_{i}(t)=(r+\mu)\left[\delta_{i}+b D_{i}(t)\right]-D_{i}(t)$

This gives us the differential equation

$$
b \dot{D}_{i}(t)=(r+\mu)\left[\delta_{i}+b D_{i}(t)\right]-D_{i}(t)
$$

Upon integration, we get

$$
D_{i}(v)=\frac{\delta_{i}(r+\mu)}{1-b(r+\mu)}+\left[D_{i}(t)-\frac{\delta_{i}(r+\mu)}{1-b(r+\mu)}\right] e^{\frac{(r+\mu) b-1}{b}(v-t)} .
$$

Substituting this $D_{i}(v)$ into (6) we get

$$
\Lambda_{i}(t)=\frac{\delta_{i}}{1-b(r+\mu)}+\left(D_{i}(t)-\frac{\delta_{i}(r+\mu)}{1-b(r+\mu)}\right) \int_{t}^{\infty} e^{-\frac{1}{b}(v-t)} d v
$$


which is equal to $\Lambda_{i}^{e}(t)=\delta_{i}+b D_{i}(t)$ if and only if $b$ is strictly positive.

\section{Proof of Lemma 2}

Substituting for $\lambda_{i}(t)$ in equation (22) using the right-hand side of (21), and rearranging we obtain

$$
\frac{d \lambda_{i}(t)}{d t}=A_{i}+B_{i} D_{i}(t)
$$

where the values of $A_{i}$ and $B_{i}$ are easy to compute.

In equation $(21)$, replace $p_{i}(t)$ by $\alpha_{i}+s_{i} D_{i}(t)$, then differentiate with respect to $t$ we obtain

$$
\frac{d \lambda_{i}(t)}{d t}=\left[-s_{j}-2 s_{i}+2 a b\right] \frac{d D_{i}(t)}{d t}
$$

In the equation (19) for $\frac{d D_{i}(t)}{d t}$ let us substitute $\alpha_{i}+s_{i} D_{i}(t)$ for $p_{i}(t)$. Then substitute the resulting expression for $\frac{d D_{i}(t)}{d t}$ in equation (47) and rearrange in order to obtain

$$
\frac{d \lambda_{i}(t)}{d t}=F_{i}+G_{i} D_{i}(t)
$$

where the values of $F_{i}$ and $G_{i}$ are easy to compute.

At a Linear Markov Perfect Equilibrium of the game it must be that, at each $t \geq 0$, and for $i=1,2, A_{i}+B_{i} D_{i}(t)=F_{i}+G_{i} D_{i}(t)$. It follows that $A_{i}=F_{i}$ and $B_{i}=G_{i}$.

Equating $B_{i}$ and $G_{i}$ for $i=1,2$, yields two equations in $s_{1}$ and $s_{2}$ :

$$
\begin{gathered}
2 a b[(r+2 \mu) \tau-2 a b \mu(r+\mu)]-\mu(r+\mu)\left(s_{1}+s_{2}\right)^{2}+ \\
\left(s_{1}+s_{2}\right)[4 a b \mu(r+\mu)-(r+2 \mu) \tau]-s_{i}(r+2 \mu) \tau=0
\end{gathered}
$$

for $i=1,2, j \neq i$.

Subtracting the second equation from the first we obtain 


$$
-(r+2 \mu)\left(s_{1}-s_{2}\right) \tau=0
$$

Not surprisingly it turns out that $s_{1}=s_{2}=s$ : the impact of a firm' $\mathrm{s}$ current market share on the price it sets is the same for both firms, regardless of the difference in capacities. Now from equations (49) we obtain the following equation for $s$ :

$$
2 a b[(r+2 \mu) \tau-2 a b \mu(r+\mu)]+s[8 a b \mu(r+\mu)-3(r+2 \mu)]-4 \mu(r+\mu) s^{2}=0(50)
$$

Equating $A_{i}$ and $F_{i}$ for $i=1,2$, yields two equations in $\alpha_{1}$ and $\alpha_{2}$, $-2(r+\mu)[\tau-\mu(a b-s)] \alpha_{i}+[\tau-2 \mu(a b-s)]\left[\left(s+\alpha_{j}+2 a \delta_{i}\right)(r+\mu)-a_{j}\right]=0$

which is $(24)$.

\section{Proof of Lemma 3}

Replace the left-hand side of equation (45) by $b d_{i}\left(D_{i}(t)\right)-\mu D_{i}(t)$ where

$d_{i}\left(D_{i}(t)\right)=\mu\left[\frac{1}{2}+\frac{\left(\alpha_{j}-\alpha_{i}\right)+s\left(1-2 D_{i}(t)\right)(r+\mu)+2 a\left(\delta_{i}+b D_{i}(t)\right)(r+\mu)-a_{j}}{2 \tau}\right]$

The resulting equation is of the form $M D_{i}+N_{i}=0$. Since this must hold for all values of $D_{i} \in[0,1]$, it follows that $M=0$, i.e.,

$$
-\left(b r \tau-\tau+b r s \mu+2 b \tau \mu+b s \mu^{2}\right)+a b^{2} \mu(r+\mu)=0
$$

and $N_{i}=0$, i.e.,

$$
\delta_{i}=\frac{b \mu\left(r s+\tau+s \mu-a_{j}+(r+\mu)\left(\alpha_{j}-\alpha_{i}\right)\right)}{2(r+\mu)(a b \mu-\tau)}
$$

\section{Proof of Lemma 5}

From equation (51) one obtains

$$
s(b)=\frac{-2 \tau(-1+b r+2 b \mu)+2 a b^{2} \mu(r+\mu)}{2 b \mu(r+\mu)}
$$


Substituting this value for $s$ in equation (50) one obtains

$$
8 \tau-10 b \tau(r+2 \mu)+2 b^{2} \tau(r+2 \mu)^{2}+b^{3}\left(a_{1}+a_{2}\right) \mu\left(r^{2}+3 r \mu+2 \mu^{2}\right)=0(53
$$

Define $X(b)=4 \tau-5 b \tau(r+2 \mu)+b^{2} \tau(r+2 \mu)^{2}+b^{3} a \mu\left(r^{2}+3 r \mu+2 \mu^{2}\right)$. This is a third-order polynomial in $b$.Let us show that this polynomial has only one positive root smaller than $\frac{1}{r+2 \mu}^{7}$.

Note first that $X(-\infty)=+\infty$ and $X(+\infty)=-\infty$ and $X(0)=$ $4 \tau>0$. Note moreover that

$$
X\left(\frac{1}{r+2 \mu}\right)=\frac{a \mu(r+\mu)}{(r+2 \mu)^{2}}<0
$$

Differentiating $X(b)$ with respect to $b$ we obtain

$$
X^{\prime}(b)=-5 \tau(r+2 \mu)+2 b \tau(r+2 \mu)^{2}+3 b^{2} a \mu(r+\mu)(r+2 \mu)
$$

Let us denote $\Delta$ the discriminant of $X^{\prime}(b)$ :

$$
\Delta=4 \tau^{2}(r+2 \mu)^{4}+60 \tau(r+2 \mu)^{2} a \mu(r+\mu)
$$

There are three possible cases, first the case where $\Delta$ is equal zero, then the case where $\Delta$ is strictly positive, and finally the case where $\Delta$ is strictly negative.

(i) $\Delta=0$ or, equivalently, $a=-\frac{\tau(r+2 \mu)^{2}}{15 \mu(r+\mu)}$, in which case $X^{\prime}(b)=0$ for only one value of $b$ which is equal to $\frac{-\tau(r+2 \mu)}{3 a \mu(r+\mu)}$.

This value corresponds to an inflection point of the function $X(b)$ and $X^{\prime}(b)<0$ for all other values of $b$. It follows that there is only one value of $b$ such that $X(b)=0$. Call this value $b^{*}$. Since $X(0)>0$ and $X\left(\frac{1}{r+2 \mu}\right)<0$ this value belongs to the open interval $\left(0, \frac{1}{r+2 \mu}\right)$.

(ii) $\Delta<0$ or, equivalently, $a<-\frac{\tau(r+2 \mu)^{2}}{15 \mu(r+\mu)}$, in which case there are no real values of $b$ such that $X^{\prime}(b)=0 . X(b)$ is everywhere strictly

\footnotetext{
${ }^{7}$ Note that this amounts to showing the uniqueness of the LMPE since the equilibrium values of $s, \alpha_{1}, \alpha_{2}, \delta_{1}$ and $\delta_{2}$ are unambiguously defined as functions of $b$.
} 
decreasing in $b$, there is only one real value of $b$ such that $X(b)=0$ and, by the same argument as above, this value belongs to the open interval $\left(0, \frac{1}{r+2 \mu}\right)$.

(iii) $\Delta>0$ or, equivalently, $a>-\frac{\tau(r+2 \mu)^{2}}{15 \mu(r+\mu)}$

Here there are two real values $b_{1}$ and $b_{2}$ of $b$ such that $X^{\prime}(b)=0$ :

$b_{1}=\frac{-\tau(2 r+4 \mu)-\sqrt{20 a \tau \mu(3 r+3 \mu)+\tau^{2}(2 r+4 \mu)^{2}}}{2 a \mu(3 r+3 \mu)}>0$

and

$b_{2}=\frac{-\tau(2 r+4 \mu)+\sqrt{20 a \tau \mu(3 r+3 \mu)+\tau^{2}(2 r+4 \mu)^{2}}}{2 a \mu(3 r+3 \mu)}>0$

There is a a local minimum of $X(b)$ at $b_{2}$ and local maximum at $b_{1}$. It follows that the polynomial $X(b)$, which has at least one strictly positive real root, may have up to three real strictly positive roots. When it has only one root we can use the same argument as before to show that it must belong to the interval $\left(0, \frac{1}{r+2 \mu}\right)$.

Let us consider the case where there are more than one real root. Let us show that only the smallest root is lower than $\frac{1}{r+2 \mu}$. We have already shown that $X\left(\frac{1}{r+2 \mu}\right)<0$ : this implies that either all the roots are lower than $\frac{1}{r+2 \mu}$ or that only the smallest root satisfies this condition. Suppose that all the roots are lower than $\frac{1}{r+2 \mu}$. It must then be that $b_{2}<b_{1}<\frac{1}{r+\mu}$. Define $b_{I}$ as the value of $b$ such that $X^{\prime \prime}\left(b_{I}\right)=0$. Then $b_{I}=-\frac{\tau(r+2 \mu)}{3 a \mu(r+\mu)}$. Clearly $b_{I}<\frac{1}{r+2 \mu} \quad$ since $\quad b_{2}<b_{I}<b_{1}$. Since we are considering here the case when $a>-\frac{\tau(r+2 \mu)^{2}}{15 \mu(r+\mu)}$ it must be that $b_{I}>\frac{5}{r+2 \mu}>\frac{1}{r+2 \mu}$, contradicting our initial assumption. We conclude that there is one and only one root of $X(b)$ which belongs to the open interval $\left(0, \frac{1}{r+2 \mu}\right)$.

Let us show that the equilibrium value, $s\left(b^{*}\right)$, of $s$ is $<0$; obviously the sign of $s(b)$ is the sign of $-2 \tau(-1+b r+2 b \mu)+b^{2} \mu(r+\mu)\left(a_{1}+a_{2}\right)$. Let us multiply this last expression by $b(r+2 \mu)$ (which is strictly positive) and then subtract $X(b)$ (which equals zero at $b=b^{*}$ ) from the resulting expression. 
We obtain a new polynomial that we'll call $S(b)$; the sign of $S\left(b^{*}\right)$ is the same as the sign of $s\left(b^{*}\right)$ :

$$
S(b)=-8 \tau+12 b \tau(r+2 \mu)-4 \tau b^{2}(r+2 \mu)^{2}
$$

$S(b)$ has two positive roots, $\frac{1}{r+2 \mu}$ and $\frac{2}{r+2 \mu}$, and is strictly negative when $b<\frac{1}{r+2 \mu}$.

\section{Proof of Proposition 1}

The equilibrium values of $\delta_{i}$ as functions of $b$ (see equations (34)), $i=1,2$, are obtained by substituting for $\left(\alpha_{i}-\alpha_{j}\right)$ in equation (27) its value from equation (28), then substituting in the resulting equation the value of $s$ from equation (52) and finally solving the system of two equations formed by the equation thus obtained (which gives $\delta_{1}-\delta_{2}$ as a function of $b$ ) and equation (16)(which gives $\delta_{1}+\delta_{2}$ as a function of $b)$.

The equilibrium values of $\alpha_{i}$ as functions of $b$ (equations (35), $i=$ 1,2 , are obtained by solving the system of equations (24) for $\alpha_{1}$ and $\alpha_{2}$, then substituting for $s$ its value from equation (52) and finally for $\delta_{1}$ and $\delta_{2}$ their values from equations (34). To show $H\left(b^{*}\right)>0$, note that the sign of $H(b)$ is the sign of its numerator, $2-b(3 r+5 \mu)+$ $b^{2}(r+\mu)(r+3 \mu)$, which is itself strictly positive for all $b \in\left[0, \frac{1}{r+\mathbf{2} \mu}\right)$, with the immediate consequence that $H\left(b^{*}\right)>0$. To show that $K\left(b^{*}\right)$ $>0$, see the proof of Proposition 3

\section{Proof of Proposition 2}

1. The steady-state price $\widehat{p}_{i}=\alpha_{i}\left(b^{*}\right)+s\left(b^{*}\right) \widehat{D}_{i}$ where $\widehat{D}_{i}$ is the steady-state market share of firm $i$. When $a_{1}=a_{2}$ it is straightforward to show that $\widehat{D}_{i}=\frac{1}{2}$. Substituting respectively for $\alpha_{i}\left(b^{*}\right)$ and $s\left(b^{*}\right)$ in the above equation their values from equations (52) and (35) one obtains equation (36).

2. From equation (36) 
$\widehat{p}_{i}-\frac{\tau}{r+\mu}=\frac{a b^{* 3} \mu(r+\mu)^{2}+\tau\left(4-b^{*}(5 r+9 \mu)+b^{* 2}(r+\mu)(r+2 \mu)\right.}{2 b^{* 2} \mu(r+\mu)^{2}}$

The sign of the RHS of the above equation is the sign of its numerator. Since $b^{*}$ must satisfy $X\left(b^{*}\right)=0$ subtract $X\left(b^{*}\right)$ from the numerator in order to obtain

$$
\operatorname{sign}\left[\widehat{p}_{i}-\frac{\tau}{r+\mu}\right]=\operatorname{sign}\left[-a b^{* 2} \mu(r+\mu)+\tau\left(1-b^{*}(r+2 \mu)\right)\right]
$$

This sign is positive since, as shown in the Proof of Proposition $1, b^{*}<\frac{1}{r+2 \mu}$.

\section{Proof of Proposition 3}

1. It follows straightforwardly from Proposition 1 that $\alpha_{1}-\alpha_{2}=$ $2 K(b)\left(a_{1}-a_{2}\right)$. Let us show that both the numerator and the denominator of $K(b)$ are strictly negative at $b=b^{*}$ so that $K\left(b^{*}\right)$ $>0$. First, from proposition $1, b^{*}<\frac{1}{r+2 \mu}=\frac{2}{2 r+4 \mu}$, so $b^{*}<\frac{2}{r+3 \mu}$ and the denominator of $K(b)$ is strictly negative at $b=b^{*}$. Next, $b^{*}<\frac{1}{r+2 \mu}=\frac{4}{4 r+8 \mu}$, so $b^{*}<\frac{4}{r+5 \mu}$ and the numerator of $K(b)$ is strictly negative at $b=b^{*}$.

2. At the steady-state $\frac{d \Lambda_{i}}{d t}=0 \Longrightarrow(r+\mu)\left(\delta_{i}+b \widehat{D}_{i}\right)-\widehat{D}_{i}=0 \Longrightarrow$ $\widehat{D}_{i}=\delta_{i} \frac{r+\mu}{1-b(r+\mu)}$. It follows that $\widehat{D}_{1}-\widehat{D}_{2}=\frac{r+\mu}{1-b(r+\mu)}\left(\delta_{1}-\delta_{2}\right)$ and we can now substitute for $\left(\delta_{1}-\delta_{2}\right)$ its value from equation (34). It remains to show that $Z\left(b^{*}\right)>0$ or equivalently, since the numerator of $Z(b)$ is strictly positive, that the denominator of $Z(b)$ is strictly positive at $b=b^{*}$. In the first place we know that $b^{*}<\frac{1}{r+\mu} \Longrightarrow-1+b^{*}(r+\mu)<0$. Then we know that $a_{i}<0$, $i=1,2$, and we have already shown above that $b^{*}<\frac{4}{r+5 \mu}$ : it follows that $a b^{2} \mu(r+\mu)+4 \tau(-4+b(r+5 \mu))<0$. 
3. The steady-state price $\widehat{p}_{i}=\alpha_{i}+s \widehat{D}_{i}$. Therefore $\widehat{p}_{1}-\widehat{p}_{2}=\left(\alpha_{1}-\right.$ $\left.\alpha_{2}\right)+s\left(\widehat{D}_{1}-\widehat{D}_{2}\right)$ and we can substitute for $\left(\alpha_{1}-\alpha_{2}\right), s$ and $\left(\widehat{D}_{1}-\widehat{D}_{2}\right)$ respectively their values from equations $(37)$, (52) and (38) in order to obtain equation (39). It remains to show that $W\left(b^{*}\right)>0$ The sign of the denominator of $W(b)$ at $b=b^{*}$ is the same as the sign of the denominator of $Z(b)$ at $b=b^{*}$ which has been shown to be positive. So the sign of $W(b)$ at $b=b^{*}$ is the sign of its numerator. Subtracting $X(b)\left(=0\right.$ at $\left.b=b^{*}\right)$ from this numerator we obtain $b \mu(1-b r)-a b^{2} \mu(r+\mu)$ which is $>0$ since $a<0$ and $b<\frac{1}{r+\mu}<\frac{1}{r}$.

4. $\widehat{c}_{i}=\frac{\widehat{D}_{i}}{K_{i}}=\frac{a_{i} \widehat{D}_{i}}{A} \Longrightarrow \widehat{c}_{1}-\widehat{c}_{2}=\frac{1}{A}\left(a_{1} \widehat{D}_{1}-a_{2} \widehat{D}_{2}\right)=\frac{1}{a} \frac{r+\mu}{1-b(r+\mu)}\left(a_{1} \delta_{1}-\right.$ $\left.a_{2} \delta_{2}\right)$. Substituting for $\delta_{1}$ and $\delta_{2}$ their values from equation (34) we obtain $\widehat{c}_{1}-\widehat{c}_{2}=\frac{1}{A}\left[\frac{a b^{3} \mu(r+\mu)^{2}+\tau\left(5-b(5 r+9 \mu)+b^{2}(r+\mu)(r+5 \mu)\right)}{2(-1+b(r+\mu))\left(a b^{2} \mu(r+\mu)+4 \tau(-4+b(r+5 \mu))\right)}\right]\left(a_{1}-\right.$ $\left.a_{2}\right)$. Subtracting from the numerator $\frac{r+\mu}{2(r+2 \mu)} X(b)\left(=0\right.$ at $\left.b=b^{*}\right)$ we obtain equation (40). It remains to show that $U\left(b^{*}\right)<0$. But the numerator of $U(b)$ is always strictly positive while the sign of the denominator is the same as the sign of the denominator of $Z(b)$ at $b=b^{*}$ which has been shown to be positive. Since $A<0$ we conclude that $U\left(b^{*}\right)<0$. 


\section{References}

d'Aspremont, Claude, Gabszewicz, Jean-Jacques and Jacques Thisse, 1979, On Hotelling's Stability in Competition, Econometrica 17, 1145-1151.

Dockner, Engelbert, Steffen Jorgensen, Ngo Van Long, and Gerhard Sorger, 2000, Differential Games in Economics and Management Science, Cambridge University Press, New York.

Doganoglu, T. , 2000, Dynamic Price Competition with Persistent Consumer Tastes, mimeo Kiel University

Driskill, R., 2001, Durable Goods Oligopoly, International Journal of Industrial Organization 19, 391-413.

Fudenberg, Drew, and Jean Tirole, 1991, Game Theory, MIT Press, Cambridge, MA.

Grilo, I., Shy, O. , Thisse, J., 2001, Price Competition when Consumers Behavior is Characterized by Conformity or Vanity, Journal of Public Economics 80, 385-408.

Karp, L., 1996. Depreciation Erodes the Coase Conjecture, European Economic Review 40, 473-490.

Leonard, Daniel, and Ngo Van Long, 1992, Optimal Control Theory and Static Optimization in Economics, Cambridge University Press.

McKie-Mason, Jeffrey K. and Hal R. Varian, 1994a, Pricing Congestible Network Resources, Department of Economics - CREST Working Paper Series: 94-09

McKie-Mason, Jeffrey K. and Hal R. Varian, 1994b, Economic FAQs About the Internet, Journal of Economic Perspectives, 8, 75-96 
Odlyzko, A.,1999, The Current State and Likely Evolution of the Internet, Proc.Globecom'99, IEEE, 1869-1875.

Scotchmer, S., 1985, Profit-Maximizing Clubs, Journal of Public Economics 27, 25-45. 